\title{
Silicon cantilevers and tips for scanning force microscopy*
}

\author{
J Brugger, R A Buser and N F de Roow \\ Instutute of Microtechnology, Untverstty of Neuchâtel Rue A-L Breguet 2, CH-2000 Neuchâtel (Switzerland)
}

(Received January 7, 1992, accepted March 20, 1992)

\begin{abstract}
Monocrystalline silicon cantilevers with integrated silicon tips for scanning force microscopy are fabricated by means of micromachining techniques Theoretical considerations including finite element modelling have been carried out in order to find a sustable shape and dimensions according to the mechanical requirements Several different cantilever designs have been fabricated a simple beam with various cross sections as well as a folded meander shape with square cross section Special attention has been paid to the application of these silicon microprobes to measure friction Moreover, high-aspect-ratio silicon tips with variable geometries are presented and their integration onto cantilevers is demonstrated Finally, the fabrication of an array of such microprobes is described, which enables multıple parallel or serial surface profiling to be achieved These integrated micromachined cantılevers have been successfully applied in standard atomic force microscope measurement systems
\end{abstract}

\section{Introduction}

Since the invention of the scanning tunnelling microscope (STM) in 1982 and its derivative the scannıng force microscope (SFM), also known as the atomic force microscope (AFM), in 1986 [1], this class of microscope has proved to be an excellent tool for analysing surfaces with atomic resolution This opened the possibility of using an alteration of the atomic constellation as a storage device or as surface preparation for catalytic purposes The first steps of this engineering on an atomic level have already been undertaken $[2,3]$ In microelectronics itself such STM/SFMs are employed as profilers Thereby the chip surface is measured in three dimensions, which in a comparison with an ideal chip allows quality control and even the localization of defects to be carried out For this application it would be very important to have arrays, which is only possible with batch-fabricated heads

Force microscopy, whose operation principle has been widely published [e g, 4-8], is an exten-

\footnotetext{
*Paper presented at the 6th International Conference on SolidState Sensors and Actuators (Transducers '91), San Francisco, CA, USA, June 24-28, 1991
}

sion of the STM, which makes it possible to investigate insulatıng materials as well a tıp of a flexible force-sensing cantilever stylus is raster scanned over the surface of the sample under investigation The forces acting between the tip and sample cause minute deflections of the cantilever, which are detected and displayed as an image with very high spatial resolution Such applications are not confined to inorganic surface analysis, but extend even to biomedicine The polymerization of fibrin could be depicted in situ, e g , [9]

The requirements for accurate force measurements are low force constants $(\approx 1 \mathrm{~N} / \mathrm{m})$ for high sensitivity and high resonance frequencies ( $>10 \mathrm{kHz}$ ) for noise filtering These requirements were first acheved with skilfully prepared m1croprobes, like cut or etched metal wires and folls By silicon micromachınıng, thın-film cantılevers of silicon dioxide $\left(\mathrm{SiO}_{2}\right)$ with a glued diamond fragment as the tip [10] or silicon nitride $\left(\mathrm{Si}_{3} \mathrm{~N}_{4}\right)$ with an integrated tip [11] were microfabricated Polycrystalline silicon cantilevers using sacrificial layer techniques [12] and monocrystallıne silicon ( $\mathrm{m}-\mathrm{S} 1)$ cantilevers using bulk micromachining have also been presented $[13,14]$

The tip-surface force interaction can be monitored quasistatically by measuring the cantılever 
deflection, e g, via a tunnelling tip [1], an optical laser beam deflection $[15,16]$, capacitively [17] or with integrated piezoresistors [18] A dynamic operation mode is also possible, and sometimes preferable, by driving the cantilever near its resonance frequency and measuring the frequency shift in the presence of a force gradient $[3,4]$

In the field of force microscopy some interest has arisen in measuring not only the force in the $z$-direction but also the force parallel to the scanning direction (say the $y$-direction), especially in studying the tribological behaviour of surfaces (friction, wear and lubrication) This interaction can be measured either by monitoring the lever's torsion as a reaction to lateral forces on the tip or, when disposing of a symmetrically built cantilever, by measuring its sideways deflection The types of cantilever construction for these two approaches are obviously not identical For torsional measurements, a flat cantilever with low torsional rigidity (see below) 1s required, whereas sideways bending implies the stiffnesses in the $z$-and $y$-directions are similar

Such an approach has been published by Neubauer et al using a round wire with iridium, tungsten and diamond tips and utılızing a capacitıve displacement sensor [19] For a micromachined cantilever a square cross section would be ideal This is no longer achievable with thin-film cantilevers, since the width of the beam would have to become smaller than $1 \mu \mathrm{m}$ This is not feasible with conventional photolithographic techniques and would complicate the readout even more

Therefore we have fabricated $\mathrm{m}-\mathrm{S} 1$ cantılevers by usıng bulk micromachining techniques with different geometries, simple beams as well as folded ones, and include finıte element modelling (FEM) studies

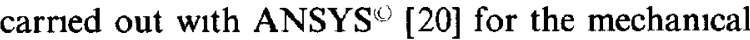
analysis and optimization of the structure Then we show the fabrication of sharp silicon tips with different heights and aspect ratios and demonstrate their integration onto the silicon cantilevers Finally, we demonstrate the suitability of batch fabrication for obtaining arrays of microprobes, enabling parallel surface profiling and an increase of the scan area versus scan time to be achieved or serial multiple-measurement to be carried out

These integrated micromachined cantilevers have been successfully applied in standard AFM measurement systems

\section{Desıgn of micromachined silicon cantilevers}

\section{Simple cantulevers}

Micromachined cantilevers from $\mathrm{Sl}_{3} \mathrm{~N}_{4}$ or $\mathrm{SiO}_{2}$ thin film were originally designed to have a high sensitivity in the vertical $z$-direction only and to be very stiff in the orthogonal directions $y$ and $x$ (inherent to thin film) By using a triangular cantilever this effect could even be increased In general, the spring constant $c_{\text {z }}$ of a simple rectangular beam cantilever is given by

$c_{z}=E w t^{3} / 4 l^{3}$

with $E$ being Young's modulus of the cantilever material and $w, l$ and $t$ the lever's width, length and thickness, respectively When aiming for a spring constant of typically $\approx 1 \mathrm{~N} / \mathrm{m}$ and assuming typical measurement forces in the range $10^{-9}$ to $10^{-6} \mathrm{~N}$, the resulting deflections of the cantilever are detectable by the readout systems described above The bending is given by Hooke's law as $\Delta z=F / c_{z}$ The first flexural resonance frequency of such a structure can be expressed by

$f_{0}=016 \frac{t}{l^{2}}\left(\frac{E}{\rho}\right)^{1 / 2}$

with $\rho$ being the material density For dynamic measurement of the frequency shift $\Delta f$ as a function of a force gradient $F^{\prime}$ we find [10]

$\Delta f=\frac{f_{0}}{2 c_{z}} F^{\prime}$

We designed simple m-Si $\left(E=169 \mathrm{E} 11 \mathrm{~N} / \mathrm{m}^{2}\right.$, $\rho=2300 \mathrm{~kg} / \mathrm{m}^{3}$ [21]) beams in various sizes feas!ble for standard microfabrication techniques to have different mechanical characteristics, as summarized in Table 1

\section{Lateral movement}

Lateral forces occurring during contact-mode measurements can be monitored by the cantilever's sideways bending $\Delta y$ related to its lateral stiffness $c_{y}$ by $\Delta y=F / c_{1}$, where

$c_{\imath}=E t w^{3} / 4 l^{3}$

This is identical with $c_{r}$ when using a quadratic cross section $(w=t)$ ( $\mathrm{cf}$ eqn (1))

In order to find a compact shape with the required specifications and to increase the bending sensitivity, we compared analytically simple beams with cantilevers of various folded forms With 
TABLE 1 Mechancal characteristics of silicon cantievers with different geometrical shapes dnd dimensions $\left(E=169 \mathrm{E}\left\|\mathrm{N} / \mathrm{m}^{2}, G=05 \mathrm{E}\right\| \mathrm{N} /\right.$ $\left.\mathrm{m}^{2} \rho=2300 \mathrm{~kg} / \mathrm{m}^{3}\right)$, for the calculation of $c_{\mathrm{k}}$ a tip length $r$ of $20 \mu \mathrm{m}$ is assumed

\begin{tabular}{|c|c|c|c|c|c|c|c|}
\hline $\begin{array}{l}\text { Length } \\
L[[\mu \mathrm{m}]\end{array}$ & $\begin{array}{l}\text { Width } \\
u[\mu \mathrm{m}]\end{array}$ & $\begin{array}{l}\text { Thickness } \\
t[\mu \mathrm{m}]\end{array}$ & $\begin{array}{l}\text { Spring constants } \\
c_{z}[\mathrm{~N} / \mathrm{m}]\end{array}$ & $c_{1}[\mathrm{~N} / \mathrm{m}]$ & $c_{v}[\mathrm{~N} / \mathrm{m}]$ & $c_{1}[\mathrm{~N} / \mathrm{m}]$ & $\begin{array}{l}\text { lst mode } \\
f_{0}[\mathrm{kHz}]\end{array}$ \\
\hline \multicolumn{8}{|c|}{ Stmple beam } \\
\hline 700 & 30 & 10 & 370 & 3326 & & 0036 & 28 \\
\hline 500 & 30 & 10 & 1014 & 9126 & & 0050 & 56 \\
\hline \multicolumn{8}{|l|}{ Meander } \\
\hline
\end{tabular}

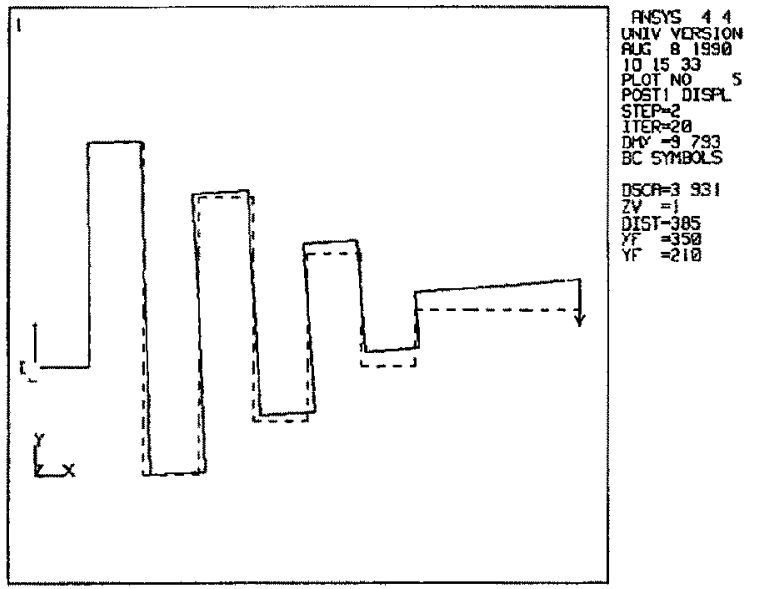

Fig I Flexural simulation of a silicon meander with dimensions $l=700 \mu \mathrm{m}$ and square cross section of $15 \mu \mathrm{m} \times 15 \mu \mathrm{m}$, applied force $10 \mu \mathrm{N}$

ANSYS" we simulated a cantılever with a square cross section of $15 \mu \mathrm{m} \times 15 \mu \mathrm{m}$ and $700 \mu \mathrm{m}$ long, folded as a meander as illustrated in Fig 1 Thus the protruding length of the microprobe could be shortened up to half of the length compared to a simple beam with the same cross section and force constant The corresponding microfabricated meander is shown in Fig 2

Since the maximal stress in both the folded and straight bent beams occurs at its clamping and is determined by its overall length times the applied force at its end (bending moment), a weaker (folded) spring bends more than a stıffer (straight) one with the same cross section until fracture The folded cantilever can thus be made more sensitive for a given force range

For this shape it is also possible to adjust the ratio of the stiffness in the $y$-and $z$-directions to a certain degree (from 1 for a simple beam to 15 for a meander with a maximal width similar to the

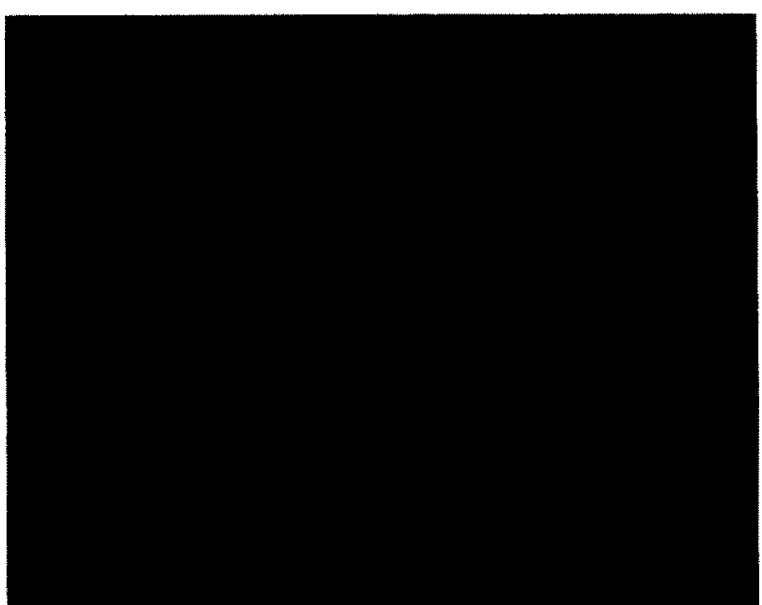

F1g 2 SEM photograph of a silicon meander corresponding to that of Fig 1

protruding length), since one movement is rather bending and the other torsionally determined The stiffness in the $x$-direction is, as required, more than one order of magnitude higher than in the measuring direction Note that the clamping of the structure is not at the central line, which decouples the $y$-movement from the $x$-movement, due to the asymmetric construction

\section{Torsional movement}

Another way to measure lateral forces is to monitor the cantilever torsion $\varphi$, which is related to the torsional rigidity $c_{\mathrm{t}}$ by $\varphi=M / c_{\mathrm{t}}$, where

$c_{\mathrm{t}}=G w t^{3} / 3 l r$

$G$ denotes the shear modulus $\left(05 \mathrm{E} 11 \mathrm{~N} / \mathrm{m}^{2}\right.$ for slicon [21]) and $r$ the tip height Depending on the geometry of the cantilever cross section as well as on $r$, the overall reaction is either more bending or torsionally determined When assuming a rigid tıp 


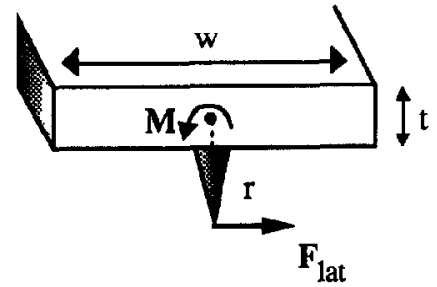

Fig 3 Illustration of the effect of lateral forces on the tip

(1 e , not behaving like a spring itself) the lever's reaction will certainly be a superposition of a bending and a torsional movement, since the force vector does not go through the centre of rotation but is applied at the tip's end A torque of $\boldsymbol{M}=\boldsymbol{r} \times \boldsymbol{F}_{\mathrm{lat}}$ thus acts on the lever (see Fig 3)

As can be seen from eqn (5), a flat cantllever $(w \gg t)$ with a high tip results in a lower torsional rigidity than one with a square cross section $(w \approx t)$, assuming the same surface area $w \times t$ By comparing eqns (4) and (5) we can evaluate the coupling of the lateral bending and torsional movements easily For this we assume a lateral force $F_{\text {lat }}$ of $10 \mu \mathrm{N}$ applied at a tip of $20 \mu \mathrm{m}$ and compare the cantilever's lateral displacement and torsional angle as a function of its cross-sectional geometry, $1 \mathrm{e}$, we vary the cross section from the square form $(15 \mu \mathrm{m} \times 15 \mu \mathrm{m})$ to a very flat form $(45 \mu \mathrm{m} \times 50 \mu \mathrm{m})$ by keeping the area constant $\left(225 \mu \mathrm{m}^{2}\right)$

The result is shown graphically in Fig 4 where the bending and torsional behaviour of a simple cantilever beam with different aspect ratios is illustrated We see clearly that a flat cantlever tends

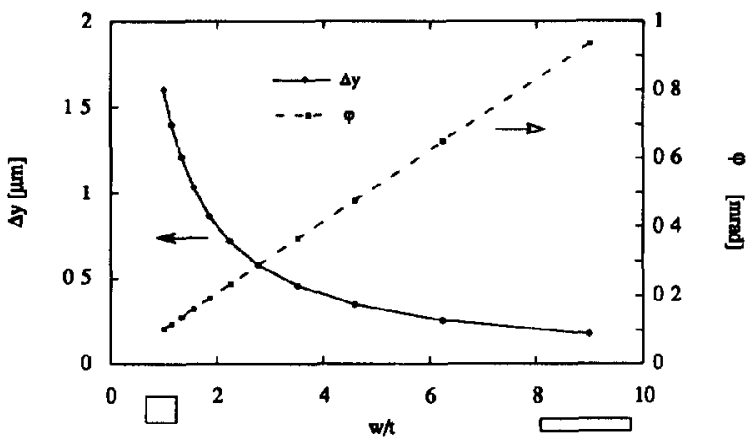

Fig 4 Bending and torsional behaviour as a function of the cantilever geometry ( $w$ and $t$ ), cantilever length $l=700 \mu \mathrm{m}$, tip height $r=20 \mu \mathrm{m}$, lateral force $F=10 \mu \mathrm{N}$, area $n \times t=225 \mu \mathrm{m}^{2}=$ const to react more by torsion (dotted curve) than a symmetrically built cantilever, which enhances the bending movement (solid curve) when the same lateral force is applied

Stress evaluation of such free-standing $\mathrm{m}-\mathrm{S}$ cantilevers has shown that for a force of $10 \mu \mathrm{N}$ at the end of the cantilever (typical measurement forces range between tenths of $\mu \mathrm{N}$ and $\mathrm{nN}$ [1]), the maximal stress at the clamping $\left(\sigma_{\max }=\right.$ $15 \times 10^{6} \mathrm{~N} / \mathrm{m}^{2}$ ) is still about two magnitudes below the fracture stress of silicon [22] It is also very well suited for resonance methods because of its very high intrinsic $Q$-factor [23]

\section{Microfabrication of sharp silicon tips}

The crucial part of the AFM point probe is the tıp, which ideally should have a curvature radius in the range of some nanometers, an aperture angle of about $5^{\circ}$ and a height of about $10 \mu \mathrm{m}$, which is crucial for an easy sample approach In the field of vacuum microelectronics both wet and dry etchıng techniques to form sharp silicon field emitters have been published [24], not all suitable for a full batch integration onto a cantilever, $\mathrm{e} g$, electron-beam deposition inside an SEM [25] or evaporation of a metal through an orifice [26] Sharp pyramidal Si tıps can be achieved with a two-stage isotropic-anisotropic etching exploiting the self sharpening due to silicon crystal plane orientation [27] or using reactive ion etching technıques with $\mathrm{SiO}_{2}$ or $\mathrm{Si}_{3} \mathrm{~N}_{4}$ etch masks [28] by exploiting the underetching of the etch mask by anisotropic etchants

We investigated methods to form tips in $\mathrm{m}-\mathrm{S}_{1}$ that are compatible with the batch microfabrication of silicon cantilevers Both dry and wet etching allow sharp tips to be formed The best results, however, are obtained by a combination of both, which has been applied to form highly protruding sharp Si tips with a high aspect ratio Instead of using a double-layer mask of $\mathrm{S}_{1} \mathrm{O}_{2}$ and photoresist (PR) [14] to perform the two-stage tıp etching, we used here only one single $\mathrm{SiO}_{2}$ etch mask for the two successive etch steps This is a major process improvement in view of the tip integration onto the cantilever, described hereafter

We patterned a $15 \mu \mathrm{m} \times 15 \mu \mathrm{m}$ square in $15 \mu \mathrm{m}$ thick thermal $\mathrm{SiO}_{2}$ and anisotropically etched a $15 \mu \mathrm{m}$ high Si column, using reactive ion etching 


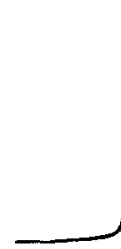

(a)

Fig 5 Tip formation exploiting a two-stage dry-anısotropic/wetisotropic etch process (a) $12 \mu \mathrm{m}$ high silicon columns obtained by RIE etching (b) Column thınning and pronounced tip formation by wet etching

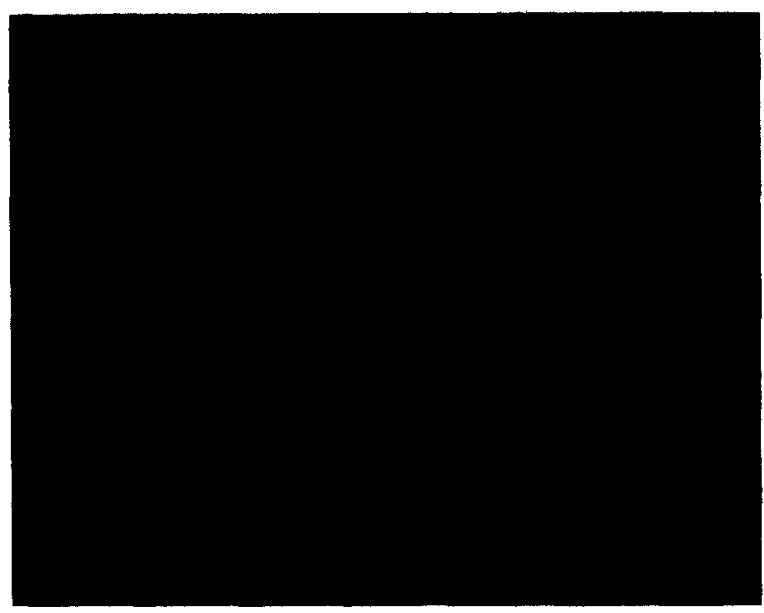

Fig 6 SEM photograph of a sharp high-aspect-ratio $\mathrm{m}-\mathrm{S}_{1}$ tip of he1ght $\approx 15 \mu \mathrm{m}$

(RIE) with a $\mathrm{C}_{2} \mathrm{ClF}_{5} / \mathrm{SF}_{6}$ gas mixture $\mathrm{W}_{1 \text { th }}$ the etch parameters the slope can be greatly influenced [29] Figure 5 shows a rather steep but not completely vertical slope Next, this structure was isotropically etched in a mixture of $\mathrm{HNO}_{3} \mathrm{HF}$ $\mathrm{CH}_{3} \mathrm{COOH}$, which thins the pre-etched shape and forms highly pronounced silicon tips Tip heights up to $20 \mu \mathrm{m}$ with opening angles of approximately 5 to $10^{\circ}$ and tip radı estimated to be $40 \mathrm{~nm}$ can be obtained with this technique (see Fig 6) A post process yielding $S_{1}$ tips with curvature radı less than $1 \mathrm{~nm}$ by reoxidization and HF etching, exploiting an anomaly of the oxidation behaviour at regions with high geometric curvature, has been demonstrated by Marcus et al [30] for other applications

When utılizing very thin high-aspect-ratıo tıps, the lateral forces occurring during tribological measurements also cause elastic deformation of the tip, $1 \mathrm{e}$, the tip will react as a spring itself In return the cantilever would bend less

\section{Batch fabrication of silicon cantilevers with integrated tips}

The fabrication of cantilevers with integrated tıps needs three photolithographies and several dry and wet etching steps, as outlined in Fig 7 Starting from a double-sıde-polıshed thermally oxıdızed silicon substrate, we performed three photolithographic and BHF etching steps in order to obtain on the backside openings for the $\mathrm{KOH}$ etching and on the topside a two-step profile $\mathrm{SiO}_{2}$ etch mask, $075 \mu \mathrm{m}$ thick for the cantilever and $15 \mu \mathrm{m}$ for the tip A membrane, typically $30 \mu \mathrm{m}$ thick, is anisotropically etched with $\mathrm{KOH}$ from the backside while protecting the topside in a mechanical chuck Then the topside is etched with $15 \mu \mathrm{m}$ deep RIE using chlorine/fluorine gas mixtures to pre-shape the cantilevers An adjustment of the RIE parameters allows vertical sidewalls of the
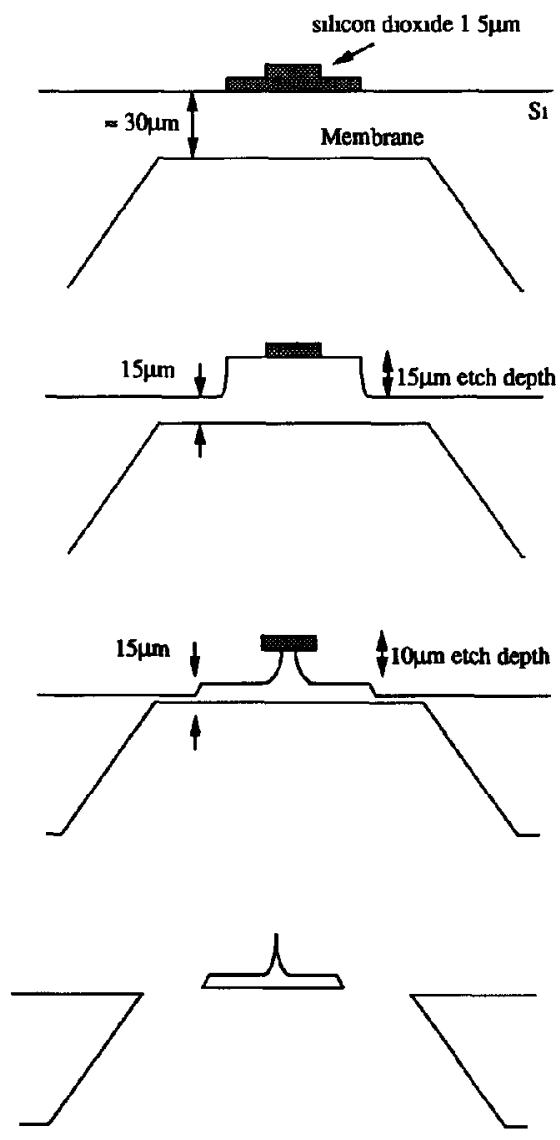

Fig 7 Microfabrication sequence of silicon cantilevers with integrated tıps (of text) 
cantilever to be obtaned The $075 \mu \mathrm{m}$ thick $\mathrm{SıO}_{2}$ mask that covered the cantılever is afterwards removed completely and the remaining oxide cap, formerly $15 \mu \mathrm{m}$ and now $075 \mu \mathrm{m}$ thıck, serves here as a mask for the tıp etching Again RIE is preferred in order to obtain high-aspect-ratio tıps and the same process parameters were used as described in the paragraph above $\mathrm{SiO}_{2}$ withstands well the three successive etch steps (1) $15 \mu \mathrm{m}$ RIE forming the cantilever shape, (11) $15 \mu \mathrm{m}$ RIE etching the silicon column for the tip, (111) $1-2$ min wet etching in $\mathrm{HF} \mathrm{HNO}_{3} \mathrm{CH}_{3} \mathrm{COOH}$ sharpening the tıp

In accordance with the different requirements for the mechanical behaviour of SFM m1croprobes, we realized cantllevers with lengths varying from 600 to $1700 \mu \mathrm{m}$ and widths from 30 to $80 \mu \mathrm{m}$ which are basically defined by the topside photolithography The cantlever thickness can be varied from $\approx 5$ to $20 \mu \mathrm{m}$ by the backside $\mathrm{KOH}$ membrane etching and the topside RIE etching For $10 \mu \mathrm{m}$ thick cantilevers, we obtain $c_{z}$ ranging from 05 to $10 \mathrm{~N} / \mathrm{m}$ and $f_{0}$ from 5 to $40 \mathrm{kHz}$ The resonance frequency for one of those cantilevers was measured with a heterodyne optical interferometer and was found to be $\approx 17 \mathrm{kHz}$ We measured a $Q$-factor for the cantilever of about 36000 in vacuum of $10^{-3} \mathrm{mbar}$

An example of an $\mathrm{m}-\mathrm{S}$ c cantilever array with an integrated tip, workable only with batch fabrication, is shown in Fig 8 The possibilities of the fabrication process presented here are illustrated in Fig 9, which demonstrates that a tip with a very

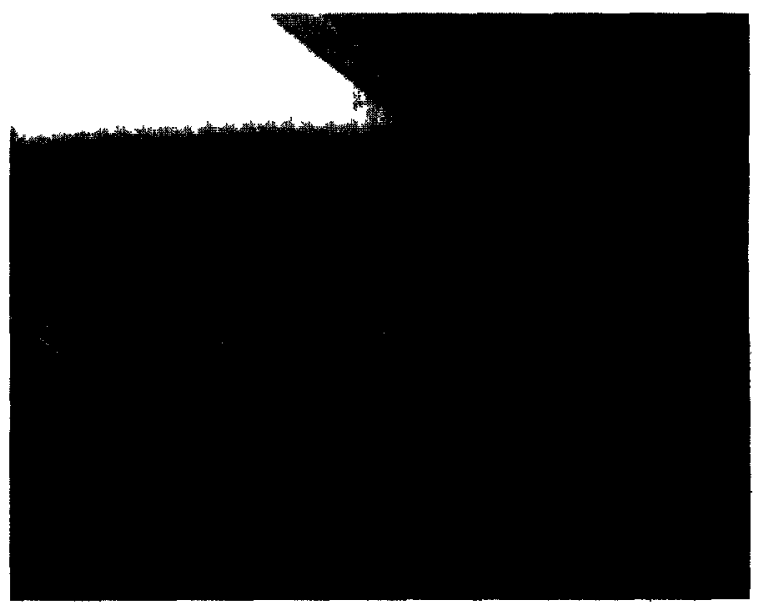

F1g 8 Array of silıcon microprobes for multiple measurements

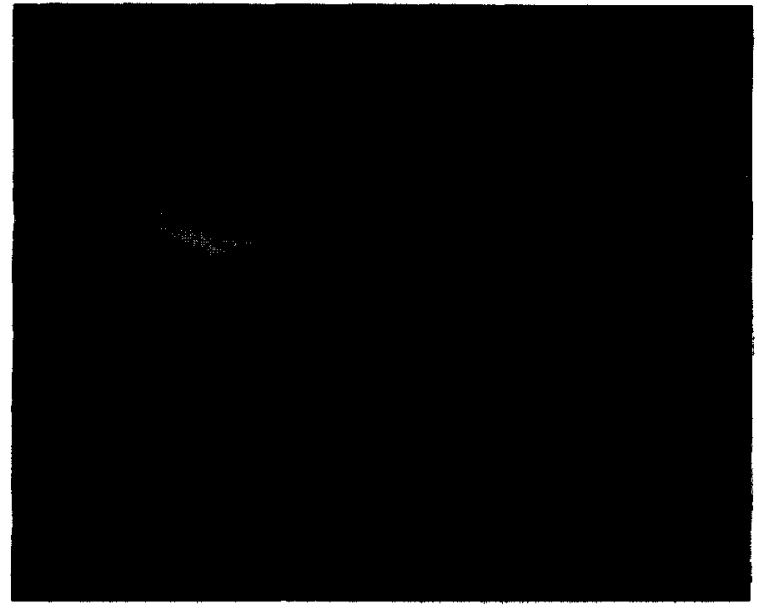

Fig 9 SEM photograph of a simple beam m-S1 cantilever with integrated tıp over an IC sample

thin 'supertıp' on top of it could be manufactured The AFM head is depicted with an IC underneath it to illustrate a possible application

\section{Application}

We constructed the holder of the cantlever so that it could easily replace commercial cantilevers in a Nanoscope ${ }^{T M}$ AFM measurement system Since an optical deflection principle is used here, cantilever compatibility was easily achieved It was thus possible to compare the characteristics of the conventional silicon nitride cantilever with our $\mathrm{m}$-S $\mathrm{S}$ ones First measurements as shown in $\mathrm{F} 1 \mathrm{~g} 10$ display promising results, with about comparable

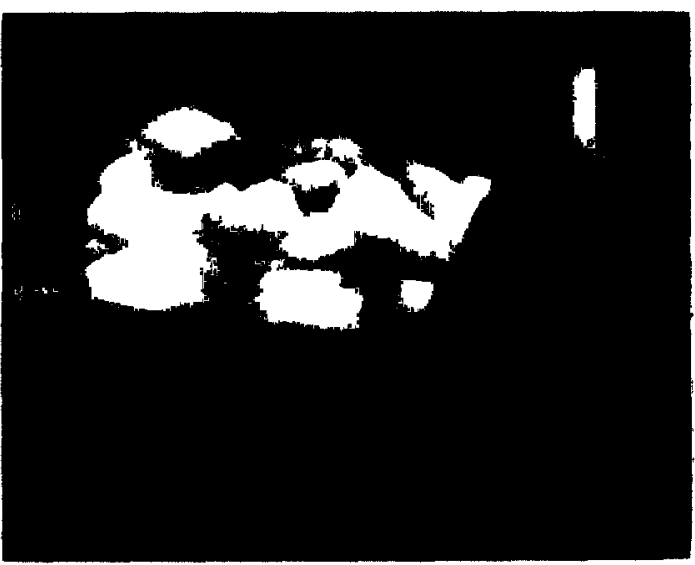

Fig 10 Thın-film diamond surface measured in a Nanoscope ${ }^{\mathrm{TM}}$ AFM with one of our integrated silicon cantilever tips 
curvatures of the thin-film diamond edges Since such an image is a convolution of the actual topography and the shape of the tip, this is an indication of the usefulness of our tips In these measurements we used a tip shape as in Fig 8 We believe that the sharp tips as shown in Fig 9 will greatly enhance the results

\section{Conclusions}

Monocrystalline silicon cantilevers with integrated silicon tips could be batch microfabricated using a three-mask process including wet and deep RIE etching techniques A microfabricated solution to allow lateral displacement of an AFM tip that is up to now unique has been demonstrated in this paper Folding the beam gave a more sensitive construction than with a straight beam of the same overall dimensions Also the feasibility of SFM arrays could be demonstrated Moreover, sharp silicon tips with a high aspect ratio, small opening angles and tıp radı of only a few tens of nanometres have been fabricated by etching techniques with results similar to those of single-processed tıps grown by an electron beam

\section{Acknowledgements}

We acknowledge $W$ Zimmermann from the University of Basel for the AFM measurements and $C$ Ketterer for the SEM photographs This work was supported by the Swiss National Science Foundation

\section{References}

$1 \mathrm{G}$ Binnig, C Quate and $\mathrm{Ch}$ Gerber, Atomic force microscope, Phys Rev Lett, 56 (1986) 930

2 U Staufer, $R$ Wiesendanger, L Eng, L Rosenthaler, H R Hidber, H J Guntherodt and N Garcia, Appl Phys Lett, 51 (1987) 244

3 R C Barrett and C F Quate, Large-scale charge storage by scanning capacitance microscopy, presented at STM ' 91 Conf Interlaken, Swttzerland, 1991

4 G M McClelland, R Erlandson and S Chiang, Atomic force microscopy general principles and a new implementation, in D O Thompson and D E Chimentı (eds), Review of Progress in Quantitative Nondestructive Evaluation, Vol 6B, Plenum, New York, 1987, p 307

5 Y Martın, C C Willams and $\mathbf{H}$ K Wickramasınghe, Atomic Imaging by 'force microscopy' with $1000 \AA$ resolution, Appl Phys Lett, 50 (1987) 1455
6 P K Hansma, V B Elıngs, O Martı and C E Bracker, Scanning tunneling microscopy and atomic force microscopy application to biology and technology, Science, 242 (1988) 209

$7 \mathrm{~K}$ Wickramasinghe, Scanning probe microscopy current status and future trends, $J$ Vac Scl Technol $A, 8$ (1990) 363

8 D Sarid, Scanning Force Microscopy, with Application to Electrtc, Magnetic, and Atomic Forces, Oxford University Press, 1991

9 S A C Gould, B Drake, C B Prater, A L Weisenhorn, S Manne, H G Hansma, P K Hansma, J Massie, M Longmire, V Elings, B Dixon Northern, B Mukergee, C M Peterson, W Stoeckentus, T R Albrecht and C F Quate, From atoms to integrated circuit chips, blood cells, and bacteria with the atomic force microscope, J Vac Sci Technol A, 8(1990) 369

$10 \mathrm{H}$ Heinzelmann, Ph $D$ Thesis, University of Basel, 1989

$11 \mathrm{~T} R$ Albrecht, S Akamıne, T E Carver and C F Quate, Microfabrication of cantilever styli for the atomic force microscope, $J$ Vac Sct Technol A, 8 (1990) 3386

12 L C Kong, B G Orr and K D Wise, A micromachined silicon scan tip for an atomic force microscope. Tech Digest, IEEE Sold-State Sensor and Actuator Workshop, Hilton Head Island, $S C$, USA, June 4-7, 1990, p 28

130 Wolter, Th Bayer and J Greschner, Micromachined silicon sensors for scanning force microscopy, $J \mathrm{Vac} S \mathrm{Sl}$ Technol $B, 9$ (1991) 1353-1357

14 R A Buser, J Brugger, C Linder and N F de Roou, Micromachined silicon cantilevers and tups for bidirectional force microscopy, Tech Digest, ath Int Conf Soldd-State Sensors and Actuators (Transducers '91), San Francisco, CA, USA, June 24-28, 1991, pp 249-252

15 G Meyer and N M Amer, Novel optical approach to atomic force microscopy, Appl Phys Lett, 53 (1988a) 2400 and Erratum Novel , Appl Phys Lett, 53 (1988b) 1045

16 D Rugar, H J Mamı, R Erlandsson, J E Stern and B T Terris, Force microscope using fiber-optic displacement sensor, Surf $S \mathrm{cl}$. 59 (1988) 2337

$17 \mathrm{~J}$ R Matey and J Blanc, Scanning capacitance microscopy, $J$ Appl Phys , 57 (1985) 1437

$18 \mathrm{M}$ Tortonese, H Yamada, R C Barrett and C F Quate, Atomic force microscopy using a plezoresistive cantilever, presented at 6 th Int Conf Soldd-State Sensors and Actuators (Transducers' '91), San Francisco, CA, USA, June 24-28, 1991, pp 448-451

19 G Neubaucr, S Cohen, G McClelland, D Horne and M Mate, Force microscopy with a bidirectional capacitance sensor, Rev Scl Instrum, 61 (1990) 2296

20 ANSYS is a well-known FEM program distributed by Swanson Analysis Systems, Inc, Houston, TX, USA

21 R A Buser, Theoretical and experimental investigations on silicon single crystal resonant structures, $P h D$ Thesis, University of Neuchâtel, 1989

$22 \mathrm{~S} \mathrm{M} \mathrm{Hu}$, Critical stress in silicon brittle fracture and effect of ion implantation and other surface treatments, $J$ Appl Phys, 53(1982) 3576

$23 \mathbf{R} A$ Buscr and N F de Roouj, Very high $Q$-factor resonators in monocrystalline silicon, Sensors and Actuators, A21-A23 (1990) $323-327$

24 Proc Second Int Conf Vacuum Microelectronics, Bath, July 24-26, 1989, ISBN 0-85498-055-5

25 Y Akama, E Nıshımura and A Sakas, New Scannıng tunnelıng microscopy tip for measuring surface topography, $J$ Vac $S C$ i Technol A, 8 (1990) 429-433

26 T R Albrecht, Advances in atomic force microscopy and scanning tunneling microscopy, $P h D$ Thesis, June 1989, Stanford University

27 P C Allen, Silicon field emitter arrays tabrication and operation, 2nd Int Conf Vacuum Microelectron, Bath, 1989, Inst Phys Conf Ser, No 99 Section 2, pp 17-20

28 J B Warren, Control of silicon field emitter shape with isotropically 
etched oxide masks, 2nd Int Conf Vacuum Microelectron, Bath, 1989, Inst Phys Conf Ser, No 99 Section 2, pp 37-40

29 C Linder, $T$ Tschan and N F de Roolj, Deep dry etching techniques as a new IC compatible tool for silicon micromachinIng, Tech Digest, 6th Int Conf Solid-State Sensors and Actuators (Transducers '91), San Francisco, CA, USA, June 24-28, 1991 pp 524-527

30 R B Marcus, T S Ravi, T Gmittcr, $K$ Chin, D Liu, W J Orvs, D R Ciarlo, C E Hunt and J Trujllo, Formation of silicon tips with $<1 \mathrm{~nm}$ radius, Appl Phys Lett, 56 (1990) 236

\section{Biographies}

Jurgen Brugger recelved his M Sc degree in physical-electronics in 1989 from the University of Neuchâtel, Switzerland $\mathrm{He}$ is now involved in research work for his $\mathrm{Ph} \mathrm{D}$ degree at the Institute of Microtechnology/Neuchâtel in the area of silicon microstructures for scanning force microscopes

Rudolf $A$ Buser received his diploma in physics from the Swiss Federal Institute of Technology in Zurich in 1982 and his Ph D from the Institute of Microtechnology (IMT) of the University of Neuchâtel, Swilzerland, in 1989 He has developed ASEP $^{\mathbb{C}}$, a code which simulates anisotropic etching of silicon and which therefore links layout with FEM programs At present he is project leader at the IMT for various sensor and actuator research projects His main interests are the dynamic prop- erties of microstructures and their modelling, especially resonance phenomena and damping

Nicolaas $F$ de Rooy received the M S degree in physical chemistry from the State University of Utrecht, The Netherlands, in 1975, and the Ph D degree from Twente University of Technology, The Netherlands, in 1978

From 1978 to 1982 , he worked at the Research and Development Department of Cordis Europa N V , The Netherlands In 1982, he joined the Institute of Microtechnology of the University of Neuchâtel (IMT), Switzerland, as professor and head of the Microfabricated Transducers Group Since October 1990, he has been acting as director of the IMT

Since 1987, he has been a lecturer at the Swiss Federal Instıtute of Technology, Zurich (ETHZ), Switzerland, and since 1989, he has also been a professor at the Federal Instıtute of Technology, Lausanne (EPFL), Switzerland His research activities include microfabricated sensors and actuators

He is a member of the steering committees of the International Conference on Sensors and Actuators and of Eurosensors $\mathrm{He}$ acted as European Charrman of Transducers ' 87 and General Chairman of Transducers ' $89 \mathrm{He}$ is a member of the editorial boards for the journals Sensors and Actuators and Sensors and Materials 